\title{
Low-Temperature Production of Genuinely Amorphous Carbon from Highly Reactive Nanoacetylide Precursors
}

\author{
Ken Judai, Naoyuki Iguchi, and Yoshikiyo Hatakeyama \\ College of Humanities and Sciences, Nihon University, 3-25-40 Sakurajosui, Setagaya-ku, Tokyo 156-8550, Japan \\ Correspondence should be addressed to Ken Judai; judai@chs.nihon-u.ac.jp
}

Received 7 September 2015; Accepted 14 March 2016

Academic Editor: Jean-Marie Nedelec

Copyright ( 2016 Ken Judai et al. This is an open access article distributed under the Creative Commons Attribution License, which permits unrestricted use, distribution, and reproduction in any medium, provided the original work is properly cited.

Copper acetylide is a well-known explosive compound. However, when the size of it crystals is reduced to the nanoscale, its explosive nature is lost, owing to a much lower thermal conductance that inhibits explosive chain reactions. This less explosive character can be exploited for the production of new carbon materials. Generally, amorphous carbon is prepared by carbonization of organic compounds exposed to high temperature, which can induce partial crystallization in graphite. In this work, we present a new method in which the carbonization reaction can proceed at a lower annealing temperature (under $150^{\circ} \mathrm{C}$ ) owing to the highly reactive nature of copper acetylide, thus avoiding crystallization processes and enabling the production of genuinely amorphous carbon materials.

\section{Introduction}

Amorphous carbon has been known for a long time under various denominations such as coal, soot, and carbidederived carbon. This form of carbon consists of free, reactive carbon, without any crystalline structure. However, most carbon materials can be categorized into diamond-likecarbon, graphite-based carbon, and carbyne, which represent the main crystalline forms of carbon, involving $\mathrm{sp}^{3}, \mathrm{sp}^{2}$, and sp carbon hybridization, respectively [1-5]. On the other hand, no apparent progress has been made in the production of genuinely amorphous carbon.

Research on the carbyne carbon form has been limited because of its instability, whereas diamond-like carbon has been studied extensively only in the last decade. Amorphous carbon is usually associated with graphite-based materials [1]. It is generally prepared by carbonization of organic compounds exposed to a high temperature, which can induce partial crystallization in graphite [6]. For the production of commercial carbon materials, graphite-based carbon is activated in order to increase its surface area. The activated carbon can no longer be considered as amorphous.

We have previously investigated the nanostructure of metal acetylide molecules and their application to gas sensors
[7], catalysis [8], and so on $[9,10]$. The explosive nature of compounds like copper acetylide has limited investigations on their use [11]. However, reducing the size of the crystals to the nanoscale eliminates their explosive nature, due to the much lower thermal conductance that inhibits explosive chain reactions. The less explosive character of the nanosized compounds can be exploited for the production of new noble carbon materials.

Herein, we report a new method for preparing genuinely amorphous carbon materials. Self-assembled copper acetylide nanowires were used as precursors for amorphous carbon [9]. As the high reactivity of copper acetylide allows the carbonization reaction to proceed at a lower annealing temperature, unwanted crystallization processes are avoided and genuinely amorphous carbon materials can be prepared. Although thin amorphous carbon films can be prepared by physical vapor deposition at low temperature [12-14], this work approach can produce amorphous carbon in bulk amounts, not in only film amounts.

In addition to the amorphous character, the new carbon material exhibited a high surface area associated with a mesoand microporous structure. Mesoporous carbon materials have recently attracted interest as viable and inexpensive materials for use in numerous applications, such as super 


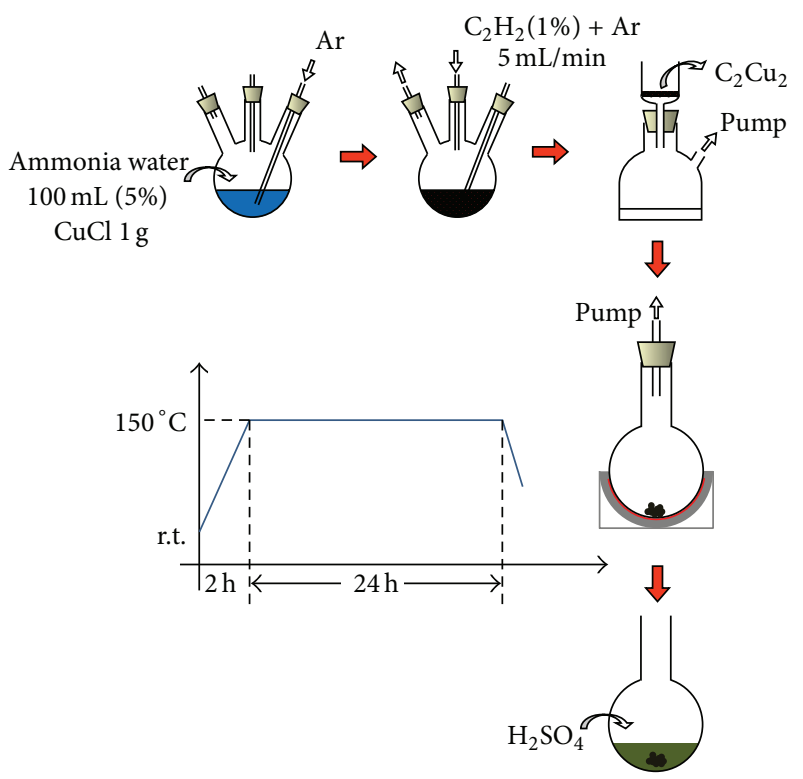

FIGURE 1: Illustration of the method used to prepare amorphous carbon under $150^{\circ} \mathrm{C}$. Copper acetylide precursor was prepared via the reaction of $\mathrm{CuCl}$ and $\mathrm{C}_{2} \mathrm{H}_{2}$ under $\mathrm{NH}_{3}$ water. Then the precursor was separated by suction filtration and annealed at $150^{\circ} \mathrm{C}$. Finally, sulfuric acid treatment was carried out for eliminating copper.

capacitors [10], absorbents, electrodes [2], and catalytic supports $[8,15]$. The unique amorphous character combined with the high surface area of the materials introduced in this work will significantly enhance its applicability in the above applications.

\section{Materials and Methods}

A schematic procedure for the preparation of amorphous carbon is illustrated in Figure 1. Copper (I) chloride (1 g) was dissolved in $5 \%$ aqueous ammonia solution $(100 \mathrm{~mL})$, and acetylene gas was introduced into the solution flask at a flow rate of $0.05 \mathrm{~mL} / \mathrm{min}$ for $3 \mathrm{~h}$, after which a dark brown precipitate of copper acetylide $\left(\mathrm{C}_{2} \mathrm{Cu}_{2}\right)$ was obtained; the chemical reaction is shown as follows:

$$
2 \mathrm{CuCl}+\mathrm{C}_{2} \mathrm{H}_{2}+2 \mathrm{NH}_{3} \longrightarrow \mathrm{C}_{2} \mathrm{Cu}_{2} \downarrow+2 \mathrm{NH}_{4} \mathrm{Cl}
$$

The extremely slow flow rate is the key to generate selfassembled $\mathrm{C}_{2} \mathrm{Cu}_{2}$ nanowires [9]. The product was separated by suction filtration and annealed under vacuum. To avoid explosive reactions, the sample was slowly heated up $\left(1^{\circ} \mathrm{C} / \mathrm{min}\right)$ to $150^{\circ} \mathrm{C}$. Carbonization of $\mathrm{C}_{2} \mathrm{Cu}_{2}$ was achieved by maintaining the sample at $150^{\circ} \mathrm{C}$ for $24 \mathrm{~h}$ for the separation reaction resulting in copper and carbon. Copper was then eliminated by dipping the sample in concentrated sulfuric acid for $30 \mathrm{~min}$. This process allowed us to obtain genuinely amorphous carbon at a temperature as low as $150^{\circ} \mathrm{C}$.

The amorphous carbon prepared as described above was analyzed by powder X-ray diffraction (XRD) measurements using $\mathrm{Cu} \mathrm{K} \alpha$ emissions (Rigaku, RINT-2000) and Raman spectroscopy with a $532 \mathrm{~nm}$ laser (Elforlight, G4 60), with the original optical setup and a $16 \mathrm{~cm}$ focusing spectrometer (Andor, SR163). The Raman signals were gathered with backscattering geometry by a microscopic objective lens and were accumulated on a CCD detector for $30 \mathrm{~min}$. This analysis was applied not only to the amorphous carbon prepared in this work but also to graphite and commercial activated carbon (Darco ${ }^{\circledR}$ G-60) samples, in order to compare their crystalline quality. Further thermogravimetric (Rigaku, TG8120) and nitrogen absorption-desorption (BEL Japan, BELSORP-mini) analyses were carried out on the amorphous carbon sample. The exact specific surface area was derived using the Brunauer-Emmett-Teller (BET) analysis from absorption-desorption data.

\section{Results and Discussion}

We have succeeded in producing carbon materials by only employing processes performed under $150^{\circ} \mathrm{C}$. The annealing temperature is one of the most important parameters to design and control the chemical properties of carbon materials. The main advantage of low-temperature carbonization is the high degree of amorphousness produced. Typical carbon materials are exposed to over $800^{\circ} \mathrm{C}$ for the carbonization, which induces crystallization of carbon to graphite [6]. In order to assess this, we have compared the spectroscopic properties of three samples: the carbon prepared in this work, graphite as an example of perfect crystalline structure, and commercial activated carbon.

The crystallinity or amorphousness can be checked by Xray diffraction measurements. Figure 2 shows powder XRD patterns for the three carbon materials examined. A strong peak was observed for graphite, denoting perfect crystallinity. Even though the measurements were taken with the same sample amounts and for the same duration, the peak intensity of the activated carbon was two orders of magnitude lower than that of graphite. This difference is due to the lower crystal quality of the carbon sample: in other words, the amorphousness of the activated carbon resulted in a lower intensity of the XRD signal. The XRD peak signal for the amorphous carbon in this work was buried in noise even for the same measuring conditions, which highlights its superior amorphousness compared to that of the activated carbon. No structural information could be obtained from the XRD measurements for the carbon material prepared in this work, owing to its highly amorphous character.

A Raman spectroscopic analysis was performed to compare in detail the three carbon materials. Figure 3 illustrates the Raman spectra of the samples excited by a $532 \mathrm{~nm}$ laser. The vertical scales of the Raman spectra were normalized in order to compare the intensities of the different samples.

The Raman spectrum for graphite (Figure 3(a)) shows the sharp G band peak at $1585 \mathrm{~cm}^{-1}$, which is the most prominent vibration of the graphite lattice. The other prominent mode is the $\mathrm{D}$ band around $1400 \mathrm{~cm}^{-1}$, which is associated with the occurrence of defects or of a large number of edges in the graphite carbon sample [1]. A large number of edges denote a small domain size in graphite. Even though no D band peak could be observed, a 2D band at double vibrational energy 


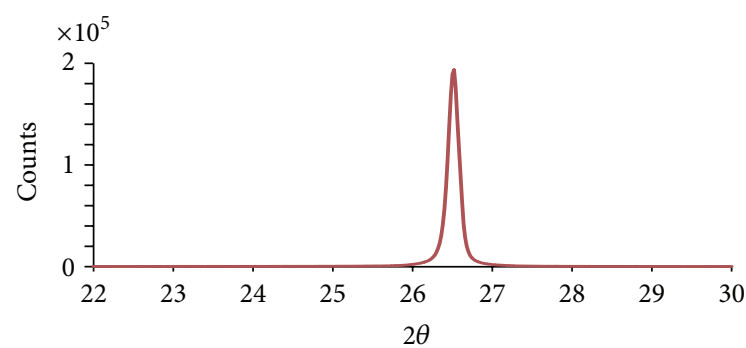

(a)

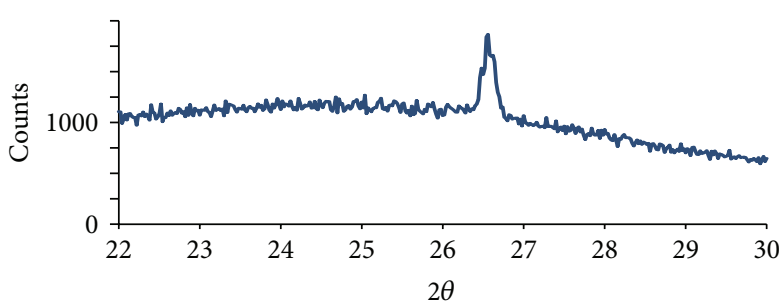

(b)

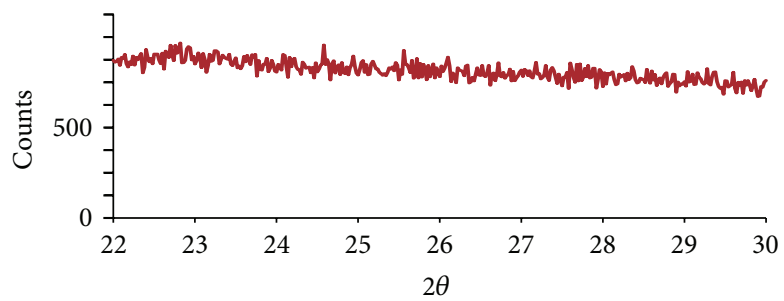

(c)

FIgURE 2: Powder X-ray diffraction patterns for graphite (a), commercial activated carbon (b), and amorphous carbon prepared in this work (c).

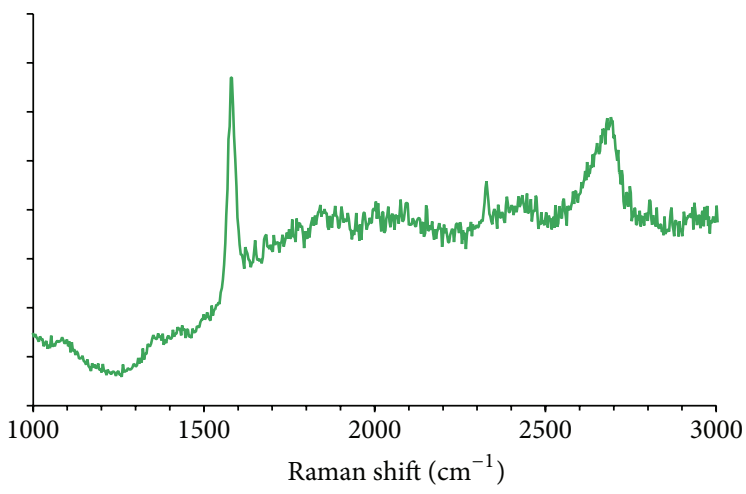

(a)

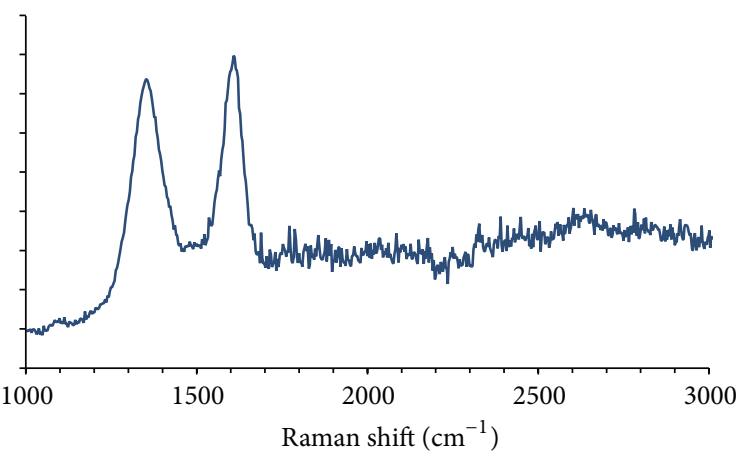

(b)

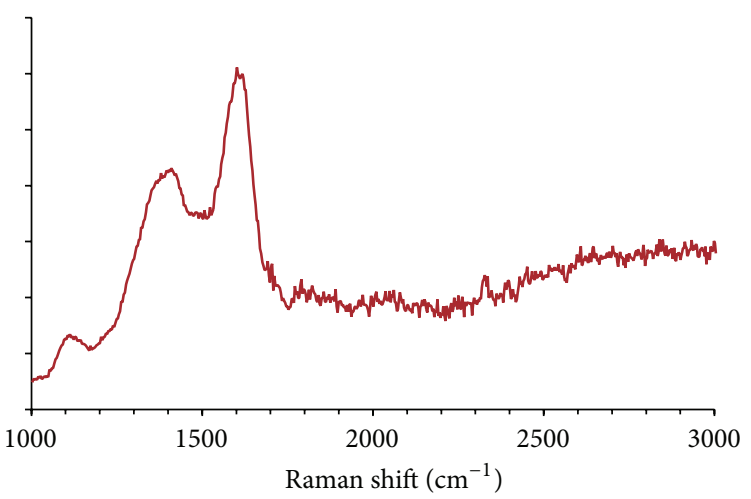

(c)

FiguRE 3: Raman spectra for graphite (a), commercial activated carbon (b), and amorphous carbon prepared in this work (c). The samples were excited by a $532 \mathrm{~nm}$ laser light with $30 \mathrm{~mW}$ power.

could be detected. The D band corresponds to an optically forbidden Raman transition, which can only occur at defect carbons or edges in graphite. However, the 2D band transition can be optically allowed even in the perfect graphite lattice.
In the Raman spectrum of activated carbon (Figure 3(b)), the $\mathrm{D}$ band can be clearly observed at $1357 \mathrm{~cm}^{-1}$, indicating that the activated carbon sample contains a large amount of defects. A comparison of the Raman spectra of graphite and 
activated carbon shows that the peak widths of the G band are also different. The chemical environments of graphitic carbon differ from those found in amorphous carbon, which manifests itself as a broad peak in the Raman spectrum. The peak width in these spectra thus represents a suitable parameter for estimating the amorphousness of a sample.

The Raman spectrum for the amorphous carbon in this work (Figure 3(c)) exhibits broader G and D band peaks than those of the activated carbon. This means that the low-temperature carbonization process can generate a carbon material of lower crystallinity and more genuinely amorphous than commercial activated carbon. The peak position of the $G$ band is $1603 \mathrm{~cm}^{-1}$, and the ratio of the $D$ band intensity to that of the G band, $I_{\mathrm{D}} / I_{\mathrm{G}}$, is 0.95 . The Raman spectrum in this work closely resembles that of an amorphous carbon film fabricated by physical vapor deposition $[1,4,12-$ 14]. However, this process can produce genuinely amorphous carbon in bulk amounts and not just in amounts required for film formation. Low-temperature carbonization is the key point to producing amorphous carbon.

It should be pointed out that the signals in the present Raman spectra can be assigned to the graphitic $G$ and $\mathrm{D}$ bands. The copper acetylide precursor of the present amorphous carbon contains a carbon-carbon triple bond. Although there are some techniques that can produce carbon materials with triply bonded carbons, the carbon triple bond of polycarbyne shows an intense Raman peak around $2000 \mathrm{~cm}^{-1}$ [16, 17]; no such polycarbyne peak can be observed in Figure 3(c). Therefore, despite using acetylide precursors, which contain carbon triple bonds, the resulting materials are based on the graphite structure. Preliminary ${ }^{13} \mathrm{C}$ NMR measurements also identified the chemical shift signals of $\mathrm{sp}^{2}$ carbon (graphite), but not of $\mathrm{sp}$ (carbyne) or $\mathrm{sp}^{3}$ (diamond) carbon. Whereas the Raman spectrum mainly provides information on the carbon hybridization, basically showing the predominance of a graphite-like carbon environment, the broadness of the $G$ band and the intensity of the D band indicate the genuinely amorphous character of the sample.

Thermogravimetric analysis was performed for the amorphous carbon prepared in this work, as shown in Figure 4. The sample was heated up at a ramp rate of $10^{\circ} \mathrm{C} / \mathrm{min}$ under atmospheric (20\%) oxygen gas concentration. Around $10 \%$ weight loss can be observed below $100^{\circ} \mathrm{C}$; this was owing to the desorption of water molecules from the carbon porous surface. The combustion of carbon starts at $150^{\circ} \mathrm{C}$. This relatively low combustion temperature denotes chemical instability of carbon. It should be pointed out that the burning temperatures of the sample spanned a wide range, from 150 to $550^{\circ} \mathrm{C}$. A wide range of different chemical environments must then be present in the amorphous carbon, and a corresponding wide range of combustion temperatures is also expected. The wide range of the temperature regions in the thermogravimetric spectrum confirms the genuinely amorphous character of the carbon prepared in this work. The total weight loss over $600^{\circ} \mathrm{C}$ reaches up to $97 \%$. The contamination of metal ash was less than $3 \%$. Considering the method used for the preparation of the samples, most of this contamination should be represented by elemental copper.

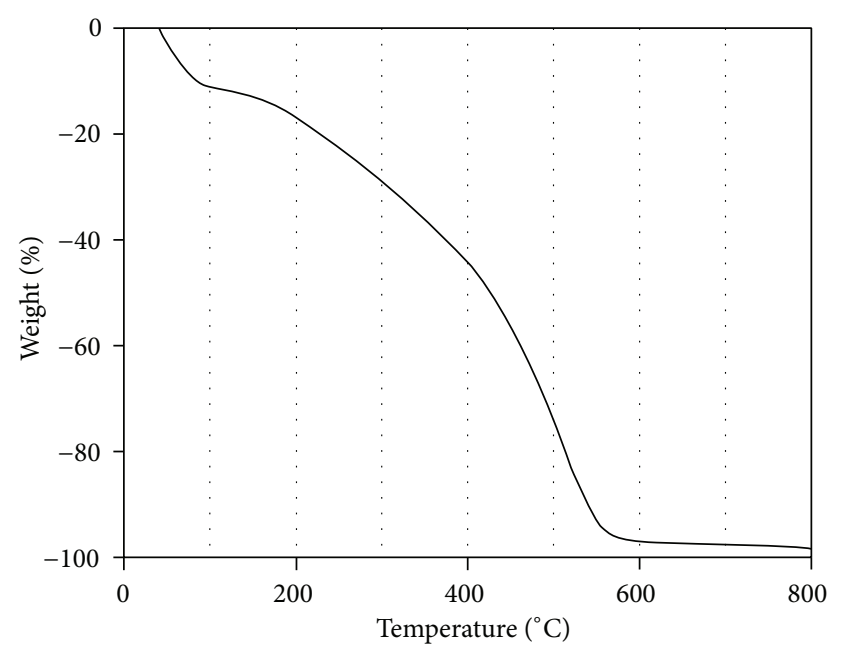

FIgURE 4: Thermogravimetric spectrum under $20 \%$ oxygen flow with a temperature ramp rate of $10^{\circ} \mathrm{C} / \mathrm{min}$.

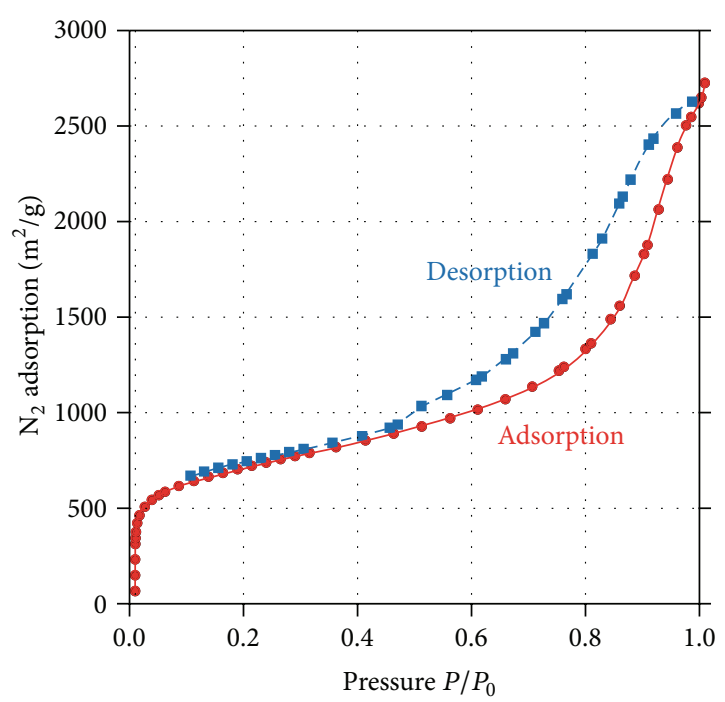

FIgURE 5: Nitrogen absorption-desorption equilibrium curves for the amorphous carbon prepared in this work. The sample was preannealed at $100^{\circ} \mathrm{C}$ for $6 \mathrm{~h}$ in vacuum and was analyzed at the liquid nitrogen temperature of $77 \mathrm{~K}$.

Nitrogen adsorption-desorption experiments were also carried out for the amorphous carbon prepared in this work. The specific surface area determined from these measurements represents one of the most important properties of carbon materials. Figure 5 shows the nitrogen adsorption and desorption isothermal equilibrium curves of the amorphous carbon. Two distinct regions are visible in the curves, a microporous region for relative pressures below 0.1 , and a mesoporous region at a relative pressure between 0.4 and 1.0. The amorphous carbon produced in this work contained substantial amounts of both microporous and mesoporous surfaces. Even though the generation method did not involve carbon activation, the microporous specific 


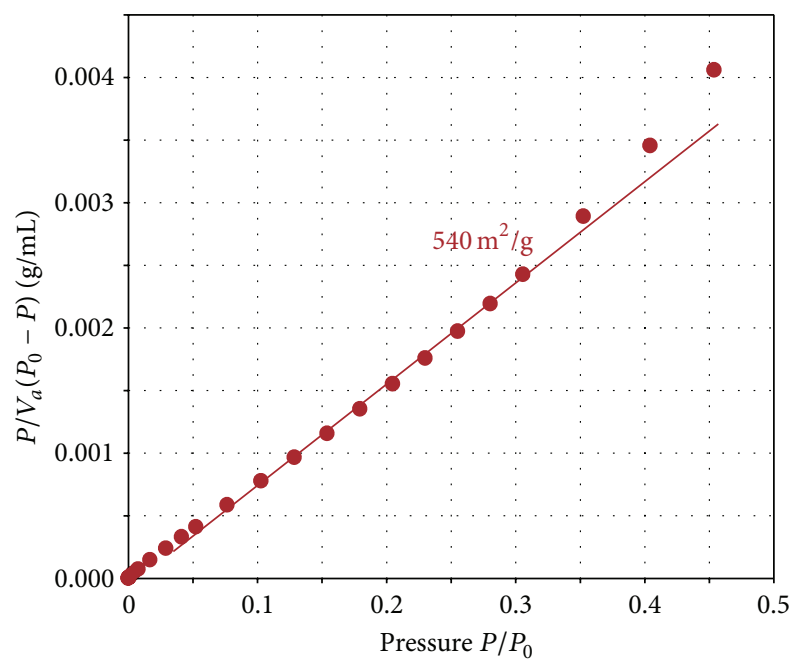

FIgURE 6: BET (Brunauer-Emmett-Teller) analysis of the absorption-desorption curves in Figure 4. A specific surface area of $540 \mathrm{~m}^{2} / \mathrm{g}$ was estimated.

surface area, obtained using BET analysis, reached values of about $540 \mathrm{~m}^{2} / \mathrm{g}$ (Figure 6).

The adsorption and desorption curve exhibits hysteresis in the mesoporous region (a mesopore is defined as a pore with diameter between 2 and $50 \mathrm{~nm}$ ); this was caused by condensation of nitrogen in the mesopores. The amorphous carbon was produced through carbonization of $\mathrm{C}_{2} \mathrm{Cu}_{2}$ followed by acid treatment to remove elemental copper. Carbonization results in the segregation of carbon and copper elements, which leads to the formation of pure copper nanoparticles of diameter between 5 and $30 \mathrm{~nm}$, as measured in a previous transmission electron microscopy study [8]. These copper nanoparticles are removed in the acid treatment, generating a porous space of the same size. The size of the copper nanoparticles and thus that of the mesopores can be controlled by the acetylide substituent. Mesoporous carbon materials have large potential for catalytic support applications, in which metal catalysis can be supported in the carbon mesopores. In fact, the catalytic application of copper nanoparticles supported in amorphous carbon has been previously investigated [8].

\section{Conclusion}

We have succeeded in preparing genuinely amorphous carbon materials. The high reactivity of copper acetylide allows the carbonization reaction to proceed at a lower annealing temperature (under $150^{\circ} \mathrm{C}$ ), and carbon materials with superior amorphousness can be prepared. In addition to the amorphous character, the new carbon material exhibited a high surface area associated with a meso- and microporous structure even though the material was produced without any activation process. The unique amorphous character combined with the high surface area will significantly enhance its applicability.

\section{Competing Interests}

The authors declare that there is no conflict of interests regarding the publication of this paper.

\section{Acknowledgments}

This work was partially supported by the N. Research Project at Nihon University. The authors acknowledge Professor Hashimoto and Dr. Niwa for technical support in the X-ray diffraction and thermogravimetric and nitrogen absorptiondesorption measurements.

\section{References}

[1] A. C. Ferrari and J. Robertson, "Interpretation of Raman spectra of disordered and amorphous carbon," Physical Review B, vol. 61, no. 20, pp. 14095-14107, 2000.

[2] L. Kavan, "Electrochemical carbon," Chemical Reviews, vol. 97, no. 8, pp. 3061-3082, 1997.

[3] A. Erdemir and C. Donnet, "Tribology of diamond-like carbon films: recent progress and future prospects," Journal of Physics D: Applied Physics, vol. 39, no. 18, article R311, 2006.

[4] J. Robertson, "Diamond-like amorphous carbon," Materials Science and Engineering R: Reports, vol. 37, no. 4-6, pp. 129-282, 2002.

[5] D. Sarangi, O. S. Panwar, S. Kumar, and R. Bhattacharyya, "Characterization studies of diamond-like carbon films grown using a saddle-field fast-atom-beam source," Journal of Vacuum Science and Technology A, vol. 18, no. 5, pp. 2302-2311, 2000.

[6] K. Barbera, L. Frusteri, G. Italiano et al., "Low-temperature graphitization of amorphous carbon nanospheres," Chinese Journal of Catalysis, vol. 35, no. 6, pp. 869-876, 2014.

[7] K. Judai, S. Numao, A. Furuya, J. Nishijo, and N. Nishi, "Increased electric conductance through physisorbed oxygen on copper nanocables sheathed in carbon," Journal of the American Chemical Society, vol. 130, no. 4, pp. 1142-1143, 2008.

[8] K. Judai, S. Numao, J. Nishijo, and N. Nishi, "In situ preparation and catalytic activation of copper nanoparticles from acetylide molecules," Journal of Molecular Catalysis A, vol. 347, no. 1-2, pp. 28-33, 2011.

[9] K. Judai, J. Nishijo, and N. Nishi, "Self-assembly of copper acetylide molecules into extremely thin nanowires and nanocables," Advanced Materials, vol. 18, no. 21, pp. 2842-2846, 2006.

[10] S. Numao, K. Judai, J. Nishijo, K. Mizuuchi, and N. Nishi, "Synthesis and characterization of mesoporous carbon nanodendrites with graphitic ultra-thin walls and their application to supercapacitor electrodes," Carbon, vol. 47, no. 1, pp. 306-312, 2009.

[11] F. Cataldo and C. S. Casari, "Synthesis, structure and thermal properties of copper and silver polyynides and acetylides," Journal of Inorganic and Organometallic Polymers and Materials, vol. 17, no. 4, pp. 641-651, 2007.

[12] M. Marton, M. Vojs, E. Zdravecká et al., "Raman spectroscopy of amorphous carbon prepared by pulsed arc discharge in various gas mixtures," Journal of Spectroscopy, vol. 2013, Article ID 467079, 6 pages, 2013.

[13] R. K. Tripathi, O. S. Panwar, A. K. Srivastava, I. Rawal, and S. Chockalingam, "Structural, nanomechanical, field emission 
and ammonia gas sensing properties of nitrogenated amorphous carbon films deposited by filtered anodic jet carbon arc technique," Talanta, vol. 125, pp. 276-283, 2014.

[14] O. S. Panwar, S. Kumar, Ishpal et al., "Effect of substrate bias in nitrogen incorporated amorphous carbon films with embedded nanoparticles deposited by filtered cathodic jet carbon arc technique," Materials Chemistry and Physics, vol. 132, no. 2-3, pp. 659-666, 2012.

[15] Y. Liu, Q. Liu, J. Gu et al., "Highly porous graphitic materials prepared by catalytic graphitization," Carbon, vol. 64, pp. 132140, 2013.

[16] S. Shiraishi, T. Kobayashi, and A. Oya, "Electrochemical lithium ion doping and undoping behavior of carbyne-like carbon film electrode," Chemistry Letters, vol. 34, no. 12, pp. 1678-1679, 2005.

[17] C. S. Casari, A. Li Bassi, L. Ravagnan et al., "Gas exposure and thermal stability of linear carbon chains in nanostructured carbon films investigated by in situ Raman spectroscopy," Carbon, vol. 42, no. 5-6, pp. 1103-1106, 2004. 

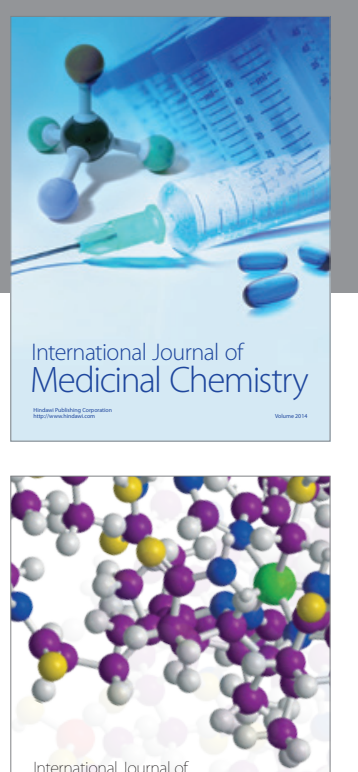

Carbohydrate Chemistry

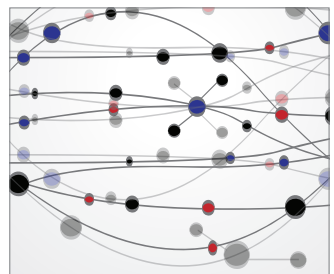

The Scientific World Journal
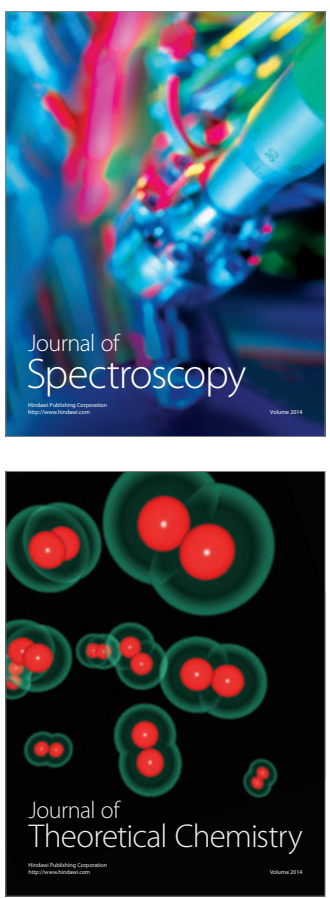
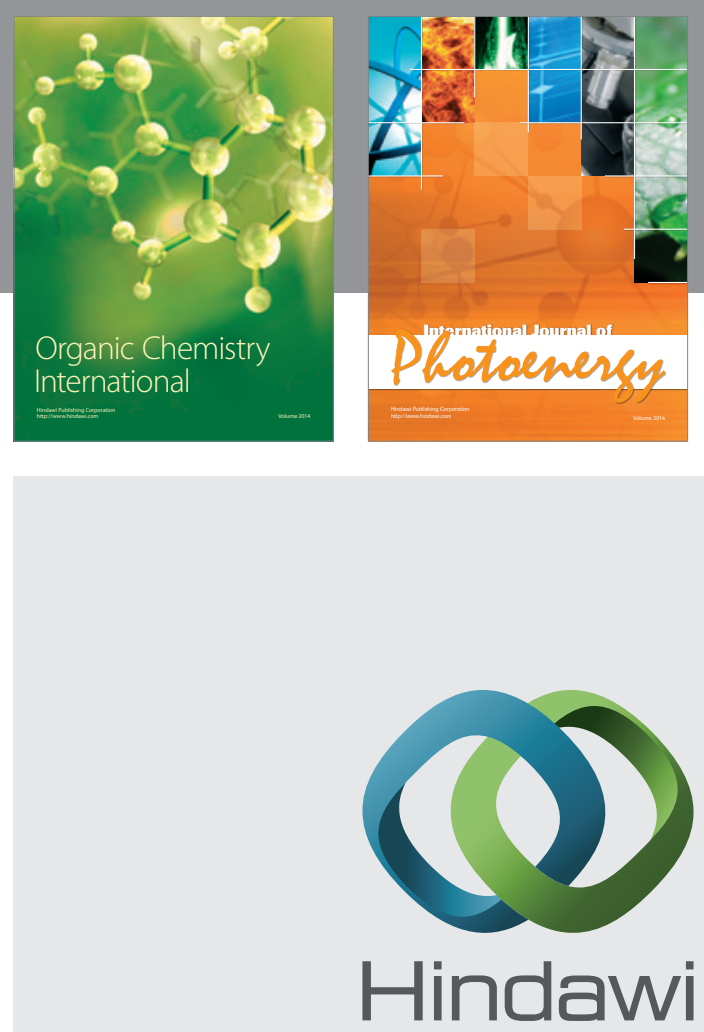

Submit your manuscripts at

http://www.hindawi.com

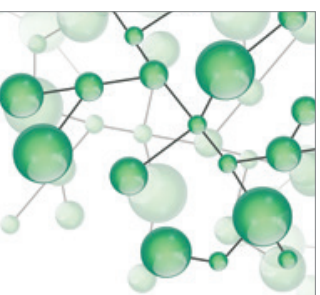

International Journal of

Inorganic Chemistry

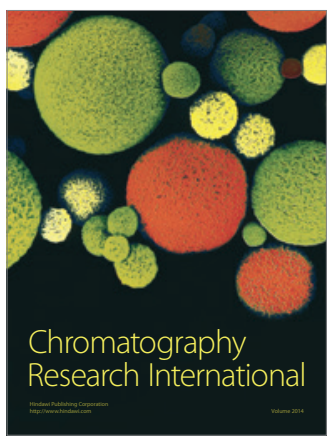

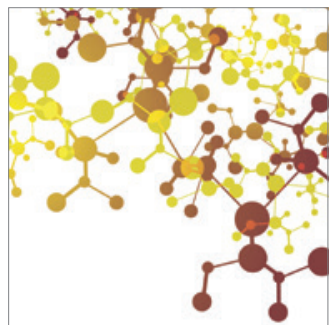

Applied Chemistry
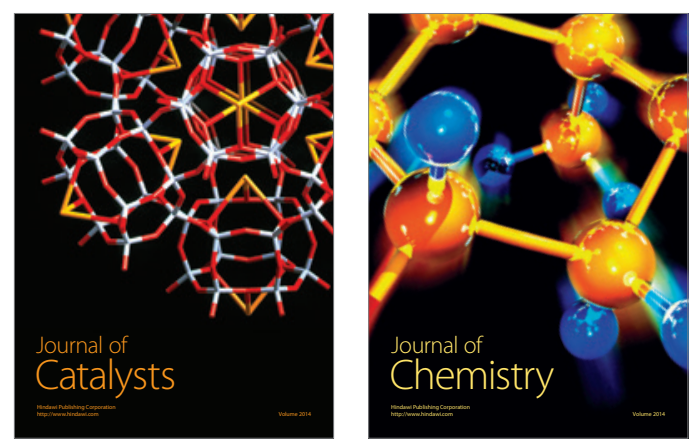
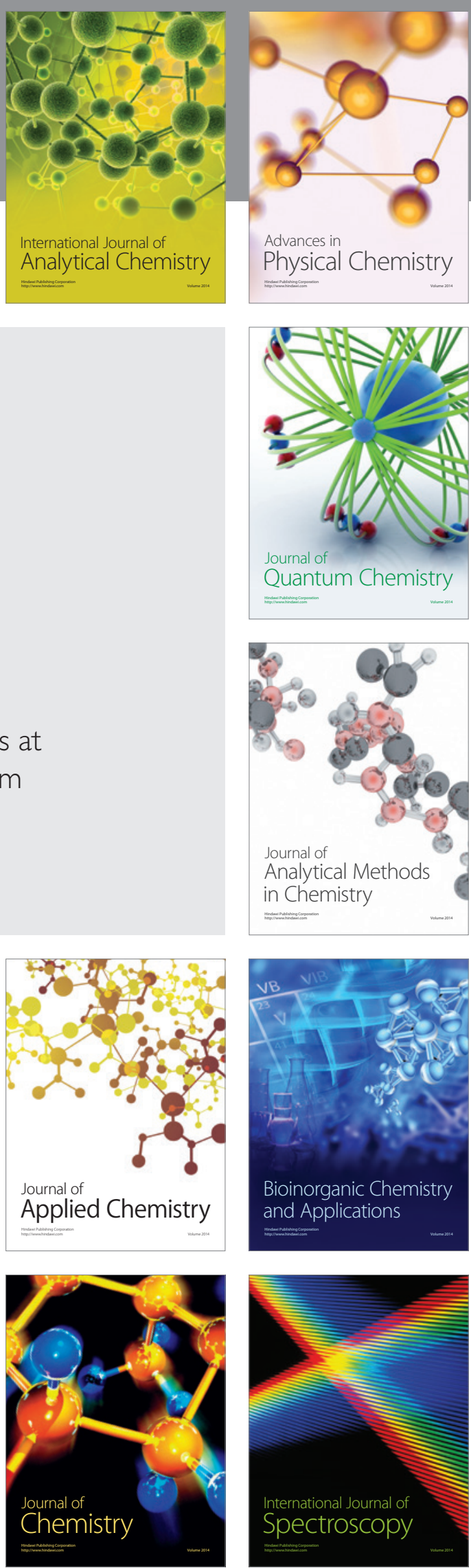